\title{
Molecular dynamics study on glass and molten state of $\mathrm{Agl}-\mathrm{AgPO}_{3}$
}

\author{
Shigeki Matsunaga* \\ National Institute of Technology, Nagaoka College, 940-8532 Nagaoka, Japan
}

\begin{abstract}
Molecular dynamics (MD) simulation on molten and glass state of $\mathrm{AgI}-\mathrm{AgPO}_{3}$ have been performed to investigate the structural features and transport properties. In MD, the screened Born-Mayer type potentials including the effect of polarizability of ions have been used. The structure, conductivity, shear viscosity, and Voronoi polyhedron are discussed in relation with the temperature change.
\end{abstract}

\section{Introduction}

The superionic conducting glasses have attracted much attention for many years as a promising candidate for the application to solid state batteries or indication devices [1,2]. Above all, a lot of examinations have been performed on the silver iodide - silver phosphate series, $(\mathrm{AgI})_{\mathrm{x}}\left(\mathrm{AgPO}_{3}\right)_{1-\mathrm{x}}$, because of some advantages. For example, the low glass transition temperature varies from $450 \mathrm{~K}$ to $350 \mathrm{~K}$ as $\mathrm{x}$ increases $[3,4]$. The ionic conductivity at room temperature is about $10^{-2} \mathrm{~S} \mathrm{~cm}^{-1}$, which is comparable to that of liquid electrolytes [3,5].

Neutron scattering experiment and Reverse Monte-Carlo (RMC) analysis have revealed that the large structure change has occurred around the glass transition temperature to form the tetrahedral structure $\mathrm{PO}_{4}$ on the glass state [6-10]. In the glass state, the infinite random chain of $\mathrm{PO}_{4}$ is formed, with $\mathrm{Ag}^{+}$ions embedded in the $\mathrm{PO}_{4}$ network. $\mathrm{Ag}^{+}$ions hop one $\mathrm{Ag}-\mathrm{O}$ bond to another. Part of $\mathrm{AgI}$ added to $\mathrm{AgPO}_{3}$ form small clusters in the network structure of $\mathrm{PO}_{4}$. Additional $\mathrm{AgI}$ clusters are expected to makes space for $\mathrm{Ag}^{+}$ions to move easily.

The molecular dynamic (MD) simulation studies have been performed to simulate the glass transition of $\mathrm{AgI}$ based conducting glass. By means of $\mathrm{MD}$, not only the structure of glass state, but also the transport properties of ions can be discussed. For $(\mathrm{AgI})_{\mathrm{x}}\left(\mathrm{AgPO}_{3}\right)_{1-\mathrm{x}}$ glass, however, no MD simulation is available in literature, to the best of our knowledge. In this study, we wish to show the MD simulation results for $(\mathrm{AgI})_{\mathrm{x}}\left(\mathrm{AgPO}_{3}\right)_{1-\mathrm{x}}, \mathrm{x}=0.5$ in its molten and glass state. The structure and transport properties will be discussed.

\section{Simulation Procedure}

The basic simulation procedure of MD of molten salt is similar to our previous simulation studies [11-14]. The background of a series of study will be briefly described as follows. The Born-Mayer-Huggins (BMH) type inter-ionic potentials are often used in MD study for AgI

*Corresponding author: matsu@nagaoka-ct.ac.jp 
based molten salts, superionic conductor, and glasses [11-17], as well as Rahman, Vashishta and Parrenello (RVP) type potentials $[18,19]$. However, the former potentials seem more profitable in describing the interaction between AgI and alkali halide, chalcogenide, or pnictogenide. In the ion conducting glasses including AgI, the conduction cation is $\mathrm{Ag}$, on the other hand the other cation and anions form the glass network structure. Under these circumstances, we have proposed the polarised and screened inter-ionic potential model based on BMH type potentials $[11,12,13]$. The screening parameters have been introduced to take into account the environmental effect by the surrounding ions, and to avoid the dispersion of potentials, i.e. the polarisation catastrophe $[11,20]$.

The used screened BMH type potentials in MD are expressed as,

$$
\begin{gathered}
\Phi_{\mathrm{ij}}(\mathrm{r})=\Phi_{\mathrm{ij}}^{0}(\mathrm{r})-\left\{1-\mathrm{f}_{\mathrm{ij}}(\mathrm{r})\right\}^{2} \frac{\mathrm{P}_{\mathrm{ij}}}{\mathrm{r}^{4}}, \\
\Phi_{\mathrm{ij}}^{0}(\mathrm{r})=\mathrm{f}^{2} \mathrm{z}_{\mathrm{i}} \mathrm{z}_{\mathrm{j}} \frac{\mathrm{e}^{2}}{\mathrm{r}}+\mathrm{A}_{\mathrm{ij}} \exp \left(-\mathrm{B}_{\mathrm{ij}} \mathrm{r}\right)-\left\{1-\mathrm{f}_{\mathrm{ij}}(\mathrm{r})\right\}^{2} \frac{\mathrm{C}_{\mathrm{ij}}}{\mathrm{r}^{6}},
\end{gathered}
$$

and

$$
P_{i j}=\frac{1}{2}\left(\alpha_{i} z_{j}^{2} e^{2}+\alpha_{j} z_{i}^{2} e^{2}\right)
$$

In Eq.2, $\mathrm{f}$ is a reduction parameter of Coulomb interaction, which represents the screening effect by the surrounding ions. $\mathrm{f}$ is assumed to be 0.4 . The second term at the right hand side of Eq. 2 is a repulsive term attributed to the overlap of electronic charges. $\mathrm{P}_{\mathrm{ij}}$ is the charge dipole interaction by the polarizability of ions $\alpha_{\mathrm{i}} . \mathrm{f}_{\mathrm{ij}}(\mathrm{r})$ in Eq.1 and 2 is the short range dumping factor introduced to avoid the dispersion of the potential [11,20]. $f_{i j}(r)$ is expressed as,

$$
\mathrm{f}_{\mathrm{ij}}(\mathrm{r})=\frac{2}{\exp \left(+\mathrm{k}_{\mathrm{ij}} \mathrm{r}\right)+\exp \left(-\mathrm{k}_{\mathrm{ij}} \mathrm{r}\right)}
$$

where the parameter $\mathrm{k}_{\mathrm{ij}}$ is given a value of 0.77 , then $\mathrm{f}_{+-}(r)$ is about 0.2 when the inter ionic distance is around 3.0A. In addition, the three body potentials are used for O-P-O and P-O-P interactions, which is expressed as,

$$
\mathrm{V}_{\mathrm{ijk}}=\mathrm{K}_{\mathrm{ijk}}\left(\theta_{\mathrm{ijk}}-\theta_{0}\right)^{2},
$$

where $\theta_{\mathrm{ijk}}$ is the bond angle for O-P-O and P-O-P [21,22]. The used potential parameters are listed in Table 1 and 2. The MD cell contains 11200 atoms (1600 AgI-AgPO ${ }_{3}$ ). The Ewald method is used for the calculation of Coulomb interaction. The numerical integration has been done using Gear algorithm for every $1 \mathrm{fs}$ time steps. The system is at first kept equilibrium at $6000 \mathrm{~K}$ in NTV, i.e. the number of atoms, the temperature, and the volume of the cell are constant. Next, the system is cooled to $2000 \mathrm{~K}$ at the rate $1 \mathrm{~K} / \mathrm{fs}$. Further cooling was performed at the rate of $0.1 \mathrm{~K} / \mathrm{fs}$ to $1000 \mathrm{~K}-400 \mathrm{~K}$, then to the temperature below the glass transition temperature $\mathrm{Tg}, 362 \mathrm{~K}[23]$.

\section{Results and Discussion}

The partial pair distribution function $\mathrm{g}_{\mathrm{ij}}(\mathrm{r})$ and the integrated coordination number $\mathrm{n}_{\mathrm{ij}}(\mathrm{r})$ for the ion pairs $i$ and $j$ are calculated by MD to analyze the short range configuration of ions. 
Table 1. Used pair potential parameters.

\begin{tabular}{|c|c|c|c|c|c|c|}
\hline ion pair & $\mathrm{Z}_{\mathrm{i}}$ & $\mathrm{Z}_{\mathrm{j}}$ & $\mathrm{A}_{\mathrm{ij}}\left(10^{-19} \mathrm{~J}\right)$ & $\mathrm{B}_{\mathrm{ij}}\left(\AA^{-1}\right)$ & $\mathrm{P}_{\mathrm{ij}}\left(10^{-19} \mathrm{~J} \mathrm{~A}^{4}\right)$ & $\mathrm{C}_{\mathrm{ij}}\left(10^{-19} \mathrm{~J} \mathrm{~A}^{6}\right)$ \\
\hline $\mathrm{Ag}-\mathrm{Ag}$ & 1 & 1 & $1.120 \mathrm{E}+03$ & 3.4483 & $0.000 \mathrm{E}+00$ & $0.000 \mathrm{E}+00$ \\
\hline $\mathrm{Ag}-\mathrm{I}$ & 1 & -1 & $5.633 \mathrm{E}+03$ & 3.4483 & $7.146 \mathrm{E}+01$ & $0.000 \mathrm{E}+00$ \\
\hline $\mathrm{Ag}-\mathrm{P}$ & 1 & 2.6 & $8.731 \mathrm{E}+02$ & 3.4483 & $3.107 \mathrm{E}+01$ & $0.000 \mathrm{E}+00$ \\
\hline $\mathrm{Ag}-\mathrm{O}$ & 1 & -1.2 & $2.236 \mathrm{E}+03$ & 3.4483 & $2.306 \mathrm{E}+01$ & $0.000 \mathrm{E}+00$ \\
\hline I - I & -1 & -1 & $2.728 \mathrm{E}+04$ & 3.4483 & $1.429 \mathrm{E}+02$ & $4.825 \mathrm{E}+02$ \\
\hline I - P & -1 & 2.6 & $4.844 \mathrm{E}+03$ & 3.4483 & $5.141 \mathrm{E}+02$ & $2.108 \mathrm{E}+02$ \\
\hline I - O & -1 & -1.2 & $1.076 \mathrm{E}+04$ & 3.4483 & $1.260 \mathrm{E}+02$ & $1.761 \mathrm{E}+02$ \\
\hline P - P & 2.6 & 2.6 & $4.909 \mathrm{E}+02$ & 3.4483 & $4.200 \mathrm{E}+02$ & $9.208 \mathrm{E}+01$ \\
\hline P - O & 2.6 & -1.2 & $1.953 \mathrm{E}+03$ & 3.4483 & $2.000 \mathrm{E}+02$ & $7.596 \mathrm{E}+01$ \\
\hline O - O & -1.2 & -1.2 & $4.237 \mathrm{E}+03$ & 3.4483 & $6.640 \mathrm{E}+01$ & $6.542 \mathrm{E}+01$ \\
\hline
\end{tabular}

Table 2. Used three body potential parameters.

\begin{tabular}{|c|c|c|}
\hline ion trio & $\mathrm{K}_{\mathrm{ijk}}\left(10^{-19} \mathrm{~J}\right)$ & $\theta_{0}(\mathrm{deg})$ \\
\hline O-P-O & 2.80382 & 109.47 \\
\hline P-O-P & 2.40327 & 135.50 \\
\hline
\end{tabular}

All $g_{\mathrm{ij}}(\mathrm{r})$ 's are shown in Fig. 1 as the examples of molten state at $1000 \mathrm{~K}$ and glass state at $280 \mathrm{~K}$, respectively. Large first peaks are seen in $\mathrm{g}_{\mathrm{IAg}}(\mathrm{r}), \mathrm{g}_{\mathrm{OAg}}(\mathrm{r})$ and $\mathrm{g}_{\mathrm{PO}}(\mathrm{r})$, which show significant correlations between $\mathrm{I}$ and $\mathrm{Ag}, \mathrm{O}$ and $\mathrm{Ag}$, and $\mathrm{P}$ and $\mathrm{O}$ ions. The first peaks of $\mathrm{g}_{\mathrm{ij}}(\mathrm{r})$ 's at $280 \mathrm{~K}$ are enhanced. Small shoulders are also seen in the larger $\mathrm{r}$ side of the first and second peaks at $280 \mathrm{~K}$, which is attributed to the fine structure in glass state.

In order to examine the detailed correlation between $\mathrm{Ag}$ and anions, the temperature dependence of $\mathrm{g}_{\mathrm{IAg}}(\mathrm{r})$ and $\mathrm{n}_{\mathrm{IAg}}(\mathrm{r})$ (left), and $\mathrm{g}_{\mathrm{OAg}}(\mathrm{r})$ and $\mathrm{n}_{\mathrm{OAg}}(\mathrm{r})$ (right) are shown in Fig.2, respectively. In both figures, the differences between molten state $1000 \mathrm{~K}-400 \mathrm{~K}$ and glass state $325 \mathrm{~K}$ and $280 \mathrm{~K}$ are observed especially in the first and second peak hights.
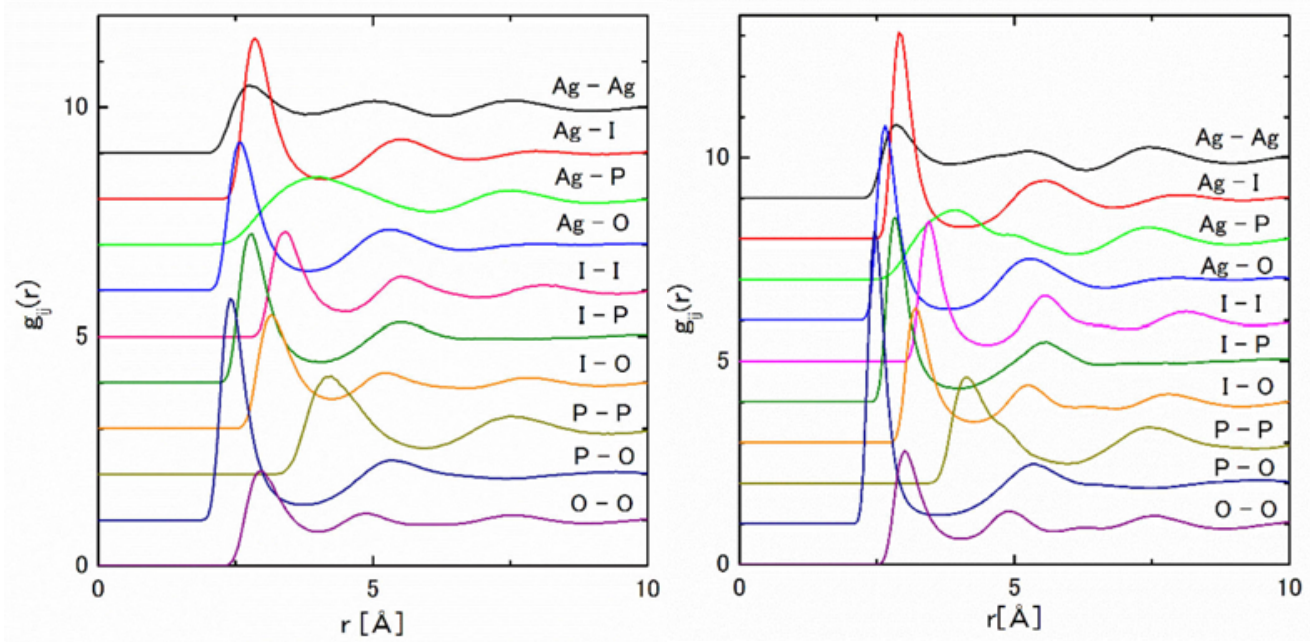

Fig.1. $\mathrm{g}_{\mathrm{ij}}(\mathrm{r})$ 's of $\mathrm{AgI}-\mathrm{AgPO}_{3}$ melt at $1000 \mathrm{~K}$ (left) , and glass at 280K (right). 

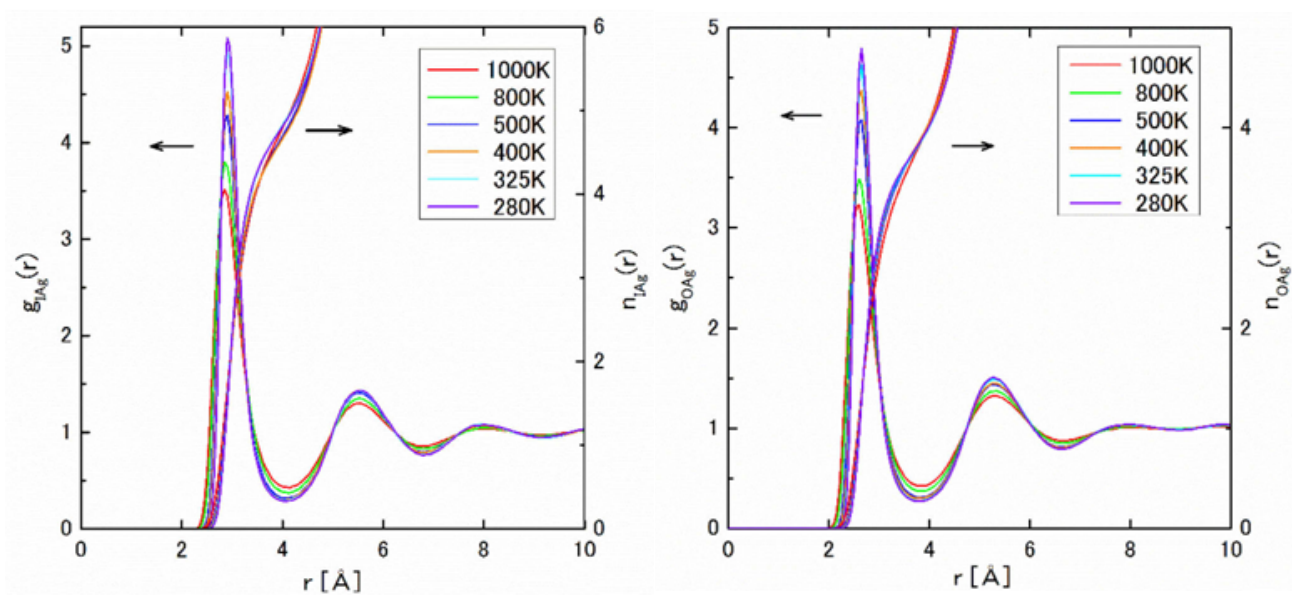

Fig.2. $\mathrm{g}_{\mathrm{IAg}}(\mathrm{r})$ and $\mathrm{n}_{\mathrm{IAg}}(\mathrm{r})$ (left), and $\mathrm{g}_{\mathrm{OAg}}(\mathrm{r})$ and $\mathrm{n}_{\mathrm{OAg}}(\mathrm{r})$ (right) for molten state $1000 \mathrm{~K}-400 \mathrm{~K}$, and glass state $325 \mathrm{~K}$ and $280 \mathrm{~K}$, respectively.

The temperature dependence in molten phase $1000 \mathrm{~K}-400 \mathrm{~K}$ is quite large, however, the structure change in glass state is rather small. The slight increase of $\mathrm{n}_{\text {IAg }}(\mathrm{r})$ at the distance of the first minimum is obseved, which may be corresponding to the decreasing tendency of the conductivity as temperature decrease. We will discuss this point later in this section.

The Voronoi polyhedron is used to analyse the structure change by glass formation. When many ions are dispersed in space, you can split the line between adjacent ions by the vertical bisection to two equal parts, then you can sepalate the whole space into Voronoi polyhedron. Therefore, the Voronoi polyhedron is a sort of an extension of the Wigner-Seitz cell for a regular crystal to the amorphous state [25]. Using the present MD results, the destribution of number of vertices of polygons, and faces surrounding Voronoi polyhedra are obtained, which are shown in Fig.3. The most superiour number of vertices is 5 in both molten and glass state, which is one of the features of the disordered system. The most superior number of faces is 13 in melt at $1000 \mathrm{~K}$, then the distribution sifts to larger number of faces in glass at $280 \mathrm{~K}$. These structure changes also suggests the glass transition of the system.

Next, we will discuss the transport properties. The conductivity $\sigma$ is connected with the diffusion coefficient $D_{\mathrm{i}}$ by the Nernst-Einstein (N-E) relation [24], as,

$$
\sigma=\sum_{i} \frac{\rho_{i} z_{i}^{2} e^{2} D_{i}}{k_{B} T}
$$

where $\rho_{\mathrm{i}}$ is the number density of the $\mathrm{i}$-th ion species. The diffusion coefficient of ions are obtainable from the slope of the mean square displacement (MSD), as,

$$
D_{\alpha}=\lim _{t \rightarrow \infty} \frac{r_{\alpha}^{2}(\mathrm{t})}{6 t}=\lim _{t \rightarrow \infty} \frac{1}{6 t N_{\alpha}} \sum_{i=1}^{N_{\alpha}}\left\langle\left|\boldsymbol{r}_{i}(t)-\boldsymbol{r}_{i}(0)\right|^{2}\right\rangle_{\alpha}
$$

where $\mathrm{i}$ stands for the $\mathrm{i}^{\text {th }} \alpha$-type ion, and $\mathrm{N}_{\alpha}$ represents its number, respectively. The angular brackets mean the average over all atomic position $\boldsymbol{r}_{\mathrm{i}}(t)$ and the time average, i.e. the ensemble average. 

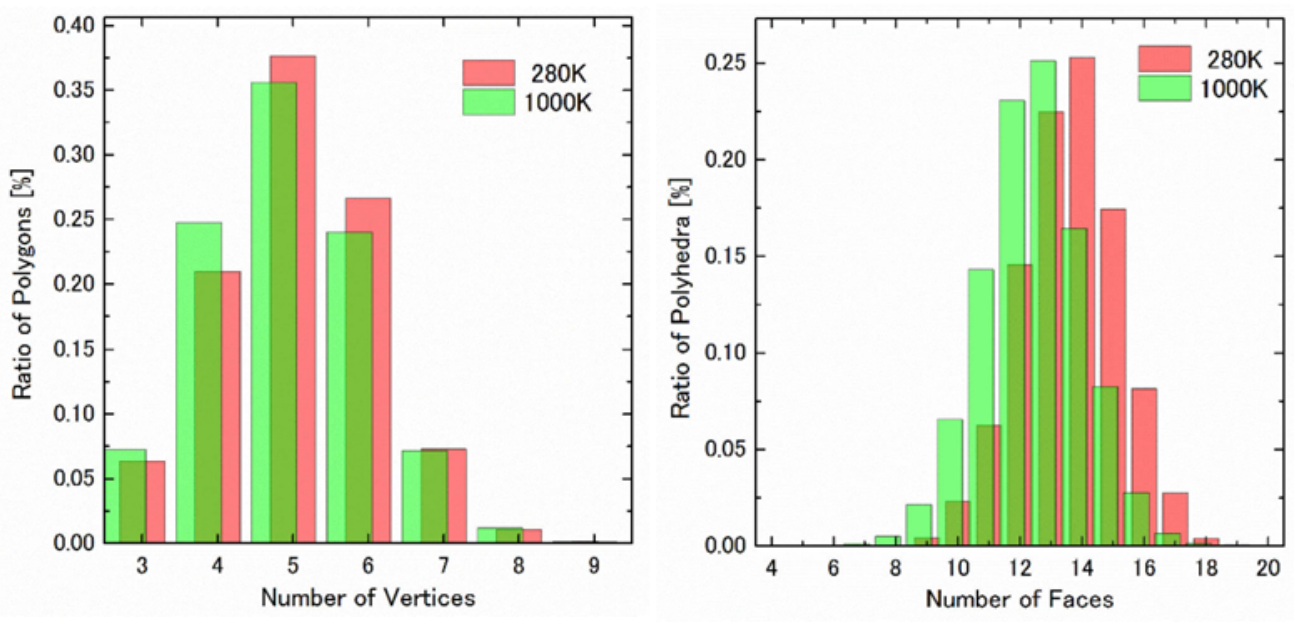

Fig. 3. Number of vertices of polygons (left) and number of faces of polyhedra (right).

In order to compare the MD results with the experimental conductivity data, the total conductivity $\sigma$ in molten phase is estimated by the diffusion coefficients of all constituent ions. In glass phase, $\sigma$ is obtained from the diffusion coefficient of Ag. The obtained $\sigma$ 's are shown in Fig.4 in comparison with the experimental data. Although there are some discrepancies between MD results and the experimental data in Fig.4 (left), the temperature dependence of $\sigma$ is reproduced in both molten and glass phases to a certain extent. A large gap of $\sigma$ is seen around the glass transition temperature. Although screening and reduction parameters are used in the pair potentials, rather smaller value of $\sigma$ comparing to the experimental data may be attributed to some overestimation of interaction between ions.

According to the Green-Kubo (G-K) formula, the shear viscosity $\eta$ is represented by the integration of the autocorrelation function of an off-diagonal element of the stress tensor in the long wave length limit, as [24],

$$
\eta=\frac{1}{k_{B} T V} \int_{0}^{\infty} \lim _{k \rightarrow 0}\left\langle\sigma_{k}^{x z}(t) \sigma_{-k}^{x Z}(0)\right\rangle d t
$$

The MD results of $\eta$ at various temperatures in molten phase are shown in Fig.4 (right) alongside the experimental data. Although the MD results are somewhat higher than the experimental data, the temperature dependence of $\eta$ by MD agrees well with the experimental data. This fact also suggests the rather larger interaction between ions.

The frequency dependent diffusion coefficient, $D_{i}(\omega)$, can be calculated from the velocity auto-correlation function $(\mathrm{VAF}),\left\langle\boldsymbol{v}_{i}(t) \cdot \boldsymbol{v}_{i}(0)\right\rangle$, as,

$$
D_{i}(\omega)=\frac{1}{3} \int_{0}^{\infty}\left\langle\boldsymbol{v}_{i}(t) \cdot \boldsymbol{v}_{i}(0)\right\rangle \cos \omega t d t
$$

$D_{A g}(\omega)$ 's for $A g$ ion obtained by MD at various temperatures are show in Fig.5. The peak heights are lowered as the temperature decreases. Although the distributions of $D_{A g}(\omega)$ 's spread over wide frequency range, the peak positions distribute around $1100 \mathrm{1} / \mathrm{cm}$ at higher temperatures, then slightly shift toward $12001 / \mathrm{cm}$ as the temperature decreases. According 

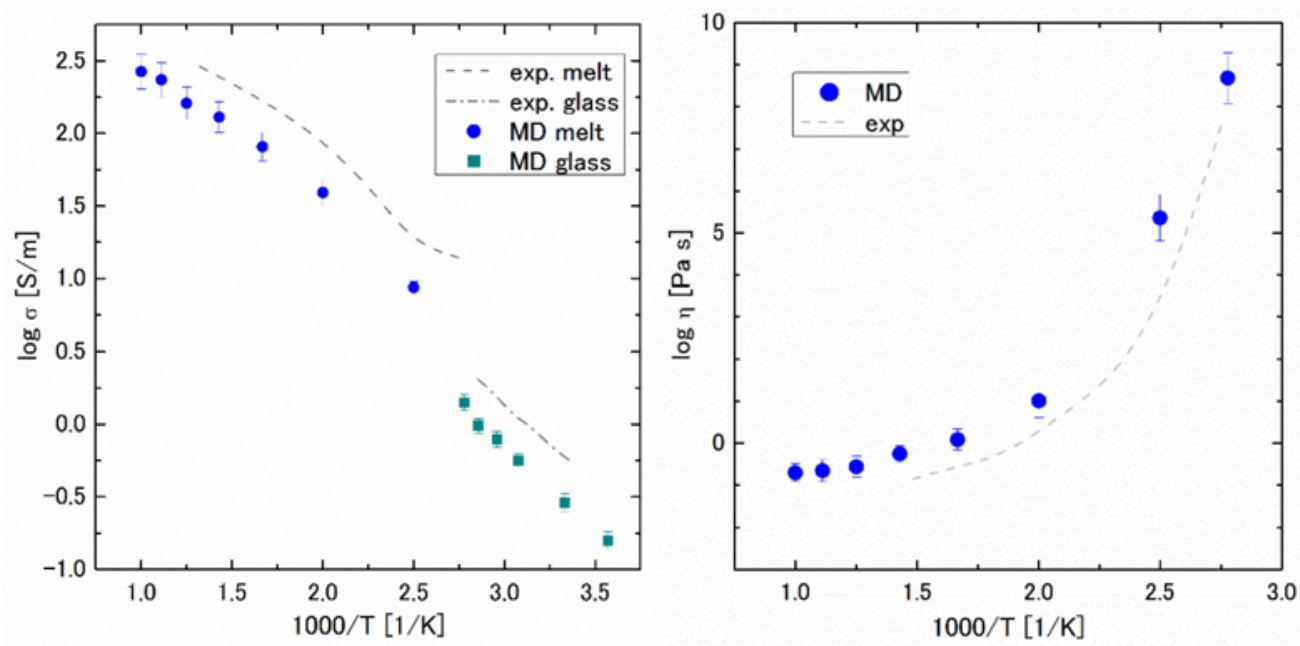

Fig. 4. $\log \sigma$ (left) and $\log \eta$ (right) obtained by MD alongside the experimental data.

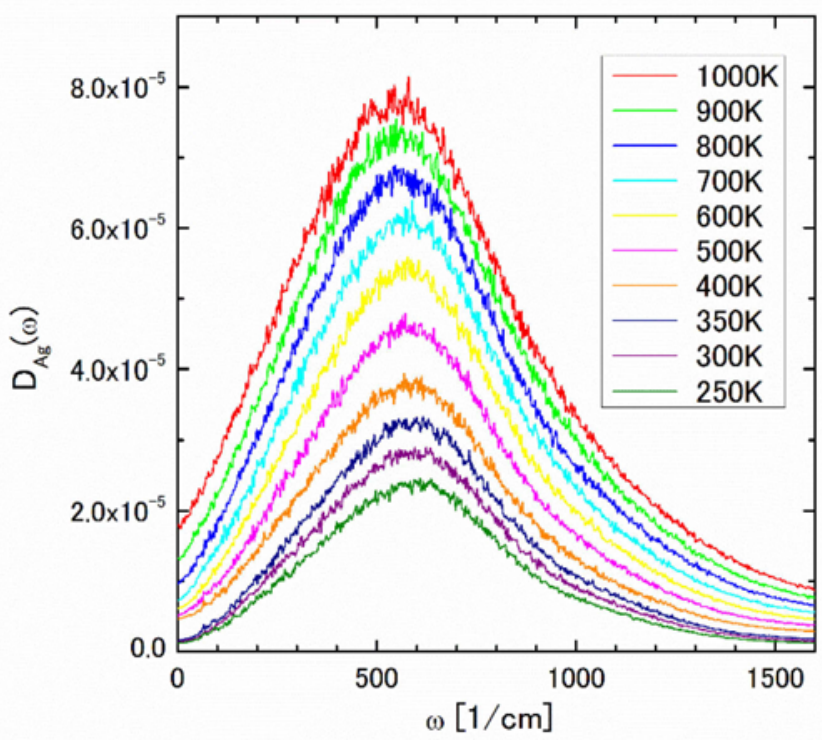

Fig. 5. $D_{\mathrm{Ag}}(\omega)$ for molten state $1000 \mathrm{~K}-400 \mathrm{~K}$, and glass state $350 \mathrm{~K}-250 \mathrm{~K}$.

to the Raman spectra experiment [26,27], the peak positions are very close to the P-O symmetric vibration mode of a long $(\mathrm{P}-\mathrm{O}-\mathrm{P})_{\mathrm{n}}$ chain $1140 \mathrm{1} / \mathrm{cm}$, which is obviously different from the modes of Ag oscillations inside of $\mathrm{O}$ cage $(85 \mathrm{1} / \mathrm{cm})$ nor in Ag-I bonding (130 - 120 $1 / \mathrm{cm})$. This fact suggests the following scenario stands to a certain extent. As AgI is doped to $\mathrm{AgPO}_{3}$, then part of $\mathrm{Ag}$ is trapped in P-O bond to form a temporal P-O-Ag bond. The diffusion of $\mathrm{Ag}$ occurs by hopping from one $\mathrm{P}-\mathrm{O}-\mathrm{Ag}$ bonding to another. In other words, most of $\mathrm{Ag}$ is vibrating in the mode of P-O-P long chain. These vibrations may affect $\mathrm{Ag}$ ions trapped in $\mathrm{AgI}$ clusters in the polymeric chains of $\mathrm{PO}_{4}$ tetrahedral units. 


\section{Conclusion}

$\mathrm{MD}$ simulations have been performed for $\mathrm{AgI}-\mathrm{AgPO}_{3}$ in molten and glass state. The structural difference between molten and glass stated have been examined by $\mathrm{g}_{\mathrm{ij}}(\mathrm{r})$ and Voronoi polyhedron analysis. The conductivity and shear viscosity have been obtained by N-E relation and G-K formula, respectively. The temperature dependence of MD results agree well with the experimental data. The distribution of $D_{A g}(\omega)$ suggests that Ag ions form the P-O-Ag bond.

\section{Acknowledgements}

The author expresses his thanks to Professor S. Tamaki for his fruitful comments and encouragement on this study. The computation was mainly carried out using the super computer facilities at Research Institute for Information Technology, Kyushu University. This work was supported by JSPS KAKENHI Grant Number JP15K05136.

\section{References}

1. M.Z.A. Munshi (ed.), Handbook of Solid State Batteries and Capacitors (World Scientific, 1995)

2. K. J. Rao, Structural Chemistry of Glasses (Elsevier, Amsterdam, 2002)

3. J.P. Malugani, A. Wasniewski, M. Doreau, G. Robert, A. Al Rikabi, Mat. Res. Bull. 13, 427 (1978)

4. C. Tomasi, P. Mustarelli, A. Magistris, Ma. P.I. Garcia, J. Non-Cryst. Sol. 293-295, 785 (2001)

5. K. Pathmanathan, R. Mlcak, P.G. Johari, Phys. Chem. Glass. 30, 180 (1989)

6. M. Tachez, R. Mercier, J.P. Malugani, P. Chieux, Solid State Ionics 25, 263 (1987)

7. J.D. Wicks, L. Börjesson, G. Bushnell-Wye, W. S. Howells, and R. L. McGreevy, Phys. Rev. Lett. 74, 726 (1995)

8. J. Swenson, S. Adams, Phys. Rev. B 64, 024204 (2001)

9. A. Thazin, Y. Fujishima, M. Arai, T. Sakuma, H. Takahashi, Solid State Ionics, 175, 675 (2004)

10. R. Magaraggia, S. Kennedy, T. Tedesco, E. Kartini, M. Collins, K. Itoh, Physica B: Condens. Matter, 385, 263 (2006)

11. S. Matsunaga, S. Tamaki, EPI Web of Conferences 15, 02010 (2011)

12. S. Matsunaga, Molecular Simulation 39, 119 (2013)

13. S. Matsunaga, Physics and Chemistry of Liquids 51, 414 (2013)

14. S. Matsunaga, Ionics 21, 161 (2015)

15. M.C. Abramo, G. Pizzimenti, A. Consolo, Phil. Mag. B 64, 495 (1991)

16. M. C. Abramo, C. Caccamo, G. Pizzimenti, J. Phys.: Condens. Matter 5 , 397 (1993)

17. A. Karthikeyan and K.J. Rao, J. Phys. Chem. B 101, 3105 (1997)

18. P. Vashishta and A. Rahman, Phys. Rev. Lett. 40, 1337, (1978)

19. M. Parrinello, A. Rahman, and P. Vashishta, Phys. Rev. Lett. 50, 1073 (1983)

20. V. Bitrián, J. Trullàs, J. Phys. Chem. B, 110, 7490, (2006)

21. E.B. Clark, R.N. Mead, G. Mountjoy, J. Phys.: Conden. Matter, 18, 6815 (2006)

22. J.-J. Liang, R.T. Cygan, T.M. Alam, J. Non-Cryst. Sol. 263-264, 167, (2000)

23. H. Kobayashi, Y. Hiki, H. Takahashi, J. Appl. Phys. 80, 122 (1996)

24. J.P. Hansen, I.R. McDonald, Theory of Simple Liquids (Academic Press, London, UK, 1986) 
25. N.F. Cusack, The Physics of Structurally Disordered Matter (Adam Hilger, Bristol, 1987)

26. E.I. Kamitsos, J.A. Kapoutsis, G.D. Chryssikos, J.M. Hutchinson, A.J. Pappin, M.D. Ingram, J.A. Duffy, Phys. Chem. Glasses 36, 141 (1995)

27. D.I. Novita, P. Boolchand, M. Malki, M. Micoulaut, J. Phys.: Condens. Matter 21, 205106 (2009) 